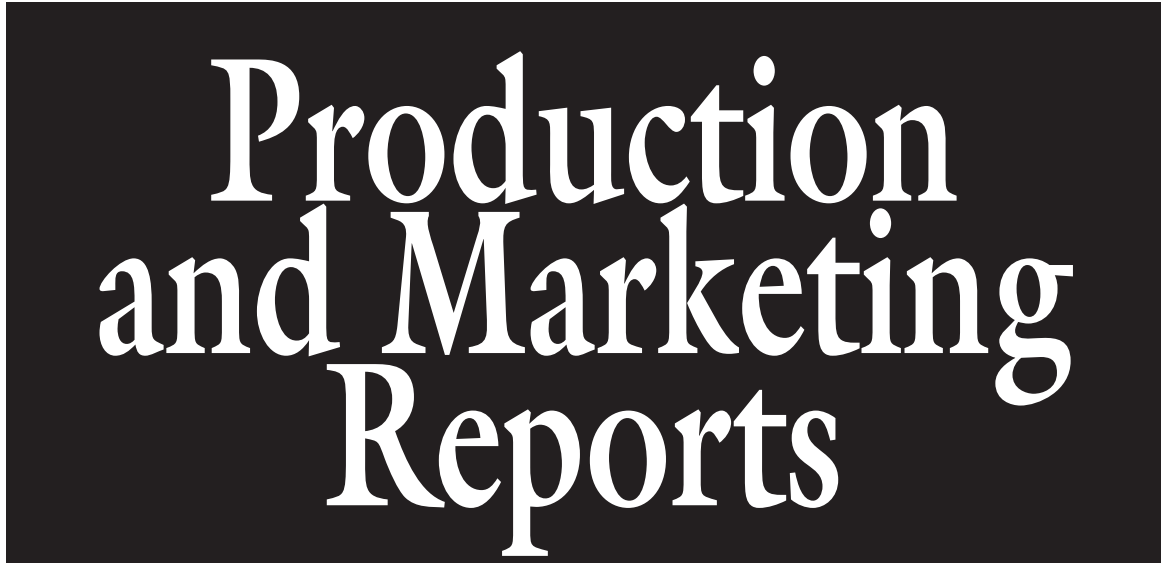

\title{
Economics of Establishing and Producing Pitaya in Southern Florida: A Stochastic Budget Analysis
}

\author{
Edward A. Evans ${ }^{1,3}$ and Jordan Huntley ${ }^{2}$
}

AdDitional index words. Hylocereus undatus, vine cactus, dragon fruit, strawberry pear, pitahaya, pitajaya, tuna, nopal, night blooming cereus

Summary. Pitaya (Hylocereus spp.), a climbing vine of cactus species native to the tropical forest regions of Mexico, Central America, and South America, has gained the attention of many southern Florida growers. Between 2006 and 2010, pitaya production has grown 6 -fold. Several factors are responsible for the increased attention being given to this crop; chief among these is the promise of high net returns stemming from the current strong demand for the fruit within an increasing U.S.-Asian population and among mainstream health-conscious U.S. consumers who are lured by the high antioxidant properties and other reported health benefits associated with the fruit. However, the downside risk associated with producing and marketing the fruit needs also to be taken into consideration before dedicating a significant amount of resources to large-scale plantings of pitaya. This article provides information on the financial feasibility of establishing and operating a 5 -acre pitaya orchard in southern Florida and assesses the risks of doing so. In conducting our analysis, we use deterministic and stochastic budgeting models, including stochastic yields and prices, to calculate the financial returns. Both the deterministic and simulation risk analysis results suggest that operating a pitaya orchard would likely be profitable over a 20 -year planning horizon. Despite the favorable outcome of the analysis, southern Florida growers are advised to proceed with caution, as the market for the crop could easily be oversupplied by domestic and foreign competitors.

$\Lambda$ s a consequence of increased foreign competition and declining returns to traditional agricultural commodities, many growers in southern Florida have embarked on a search for viable alternative agricultural commodities. One commodity that has gained the attention of southern

\footnotetext{
Tropical Research and Education Center, University of Florida, 18905 SW 280 Street, Homestead, FL 33031

${ }^{1}$ Associate Professor

${ }^{2}$ Intern
}

${ }^{3}$ Corresponding author. E-mail: eaevans@ufl.edu.
Florida growers is pitaya, also known as dragon fruit, a climbing vine of cactus species native to the tropical forest regions of Mexico, Central America, and
South America (Mizrahi et al., 1997). From less than 50 acres planted in Florida as recently as 2006 (Steele and Crane, 2006), production has grown 6-fold and is now estimated to be from around 320 acres (J.H. Crane, personal communication).

Several factors are responsible for the increased attention being given to this crop. Chief among these is the promise of high net returns stemming from the current strong demand for the fruit within an increasing U.S.Asian population and among mainstream health-conscious U.S. consumers who are lured by the high antioxidant properties and other reported health benefits associated with the fruit. Further bolstering the demand is the growing attraction being displayed by chefs at high-end restaurants for the fruit owing to its unique taste, beauty, and versatility. In addition, the fruit can be eaten fresh by itself or as an ingredient in recipes such as fruit salads, juice, desserts, jam, ice cream, cocktails, and wine (Lobo and Bender, 2008).

The crop also exhibits certain desirable and distinctive agronomic features/characteristics that enhance its prospects as a suitable and viable replacement commercial crop. These features include the relative ease with which it can be propagated (by cuttings), hence reducing the expense normally associated with the purchasing of additional planting material; the simple agronomic practices required once the crop has been established; and the short turnaround growing period, compared with other traditional fruit trees. The time from planting until harvesting begins is only 12 to 18 months, and the yields range from about 20 to $60 \mathrm{lb}$ per plant (Gunasena et al., 2006). In addition, it is a perennial crop, with a life span of 20-30 years, ensuring that with proper care, the crop can provide a steady stream of income (Crane and Balerdi, 2005; Gunasena et al., 2006).

\begin{tabular}{lllc}
\hline $\begin{array}{l}\text { Units } \\
\begin{array}{l}\text { To convert U.S. to SI, } \\
\text { multiply by }\end{array}\end{array}$ & U.S. unit & SI unit & $\begin{array}{l}\text { To convert SI to U.S., } \\
\text { multiply by }\end{array}$ \\
\hline 0.4047 & $\mathrm{acre}(\mathrm{s})$ & $\mathrm{ha}$ & $2.471 \mathrm{l}$ \\
0.3048 & $\mathrm{ft}$ & $\mathrm{m}$ & 3.2808 \\
0.0283 & $\mathrm{ft}^{3}$ & $\mathrm{~m}^{3}$ & 35.3147 \\
3.7854 & $\mathrm{gal}$ & $\mathrm{L}$ & 0.2642 \\
2.54 & inch(es) & $\mathrm{cm}$ & 0.3937 \\
0.4536 & $\mathrm{lb}$ & $\mathrm{kg}$ & 2.2046 \\
1.1209 & $\mathrm{lb} / \mathrm{acre}$ & $\mathrm{kg} \cdot \mathrm{ha}^{-1}$ & 0.8922
\end{tabular}


Notwithstanding the aforementioned desirable features associated with the crop, as pointed out by Evans (2006), starting any new enterprise can be risky, and so a careful assessment must be made to determine if a particular type of enterprise is suitable for a particular producer. While this is true for any agricultural operation, assessment is especially important in the case of pitaya, given that this crop is relatively new to growers in southern Florida; involves a longterm investment that requires a substantial amount of initial capital outlay; and unlike row or field crops, once established it is costly to undo this type of operation. Moreover, there are higher production and marketing risks owing to the increased incidence of pests and diseases, wide fluctuations in marketable yields, capricious output prices, and escalating labor costs (J.H. Crane and C.F. Balerdi, personal communication; Palmateer and Ploetz, 2006). Added to the uncertainty is the recent decision by the U.S. Department of Agriculture's Animal and Plant Health Inspection Service (USDA, 2008) to lift the ban on imports of fresh pitaya from Vietnam, the largest producer and exporter of pitaya. An increased influx of pitaya is bound to have an adverse impact on the prices the southern Florida growers would receive. Such downside risks need to be considered before dedicating a significant amount of resources to large-scale plantings of pitaya. Consequently, the objective of this study is to provide information on the financial feasibility of operating a 5 -acre pitaya orchard in southern Florida and to assess the risks of doing so, given these recent developments. In conducting our analysis, we use deterministic and stochastic budgeting models, including stochastic yields and prices, to calculate the financial returns.

\section{Materials and methods}

Information used in the analysis was obtained by a combination of interviews with growers, nursery operators, packinghouses, chemical suppliers, and other agricultural input retailers in the Homestead area of southern Florida (Evans et al., 2010). A questionnaire was prepared by the researchers to guide the interview process, which included questions pertaining to the establishment and operation of a pitaya orchard. Information was gathered over Summer 2010 via firstperson interviews and phone calls when primary interviews were not feasible. In addition to the interviews, other estimates were gathered from extension agents of University of Florida and from the existing literature. The following is a list of the major assumptions used in the model:

Land-The study assumed that land was purchased at $\$ 40,000$ per acre on the basis of the current market price. The budget and production cost items were based on a 5-acre orchard, the minimum-sized farm that is allowed.

Orchard Layout-Trellises were assumed to be placed in the orchard using a 5 -ft-long by 15 -ft-wide spacing pattern $(5 \mathrm{ft}$ between trellises and $15 \mathrm{ft}$ between rows) for a total of 581 trellises per acre. Three cacti were planted at each trellis, totaling 1743 cacti per acre.

Trellis System-Many trellis designs are used in southern Florida. For our analysis, each trellis consisted of one 8 -ft-long by 5 -inch-wide fence post planted 2-ft-deep through the center of a 65 -gal container that was filled with $6.7 \mathrm{ft}^{3}$ of potting soil. Two holes were drilled at the top of the post, and two 2 -ft-long pieces of no. 3 reinforcing bar (rebar) were inserted into the holes. A 4-ft-long piece of hog-wire fencing was then attached to the rebars. The trellis system cost was estimated at $\$ 32$ per trellis.

Species-A generic Vietnamese white flesh species (Hylocereus undatus) was chosen. This particular species was chosen on the basis of its ability to produce high volumes of fruit, compared with other sweeter species that produce less fruit.

Fertilization-Fertilizer treatments included four treatments per year of $8 \mathrm{~N}-1.3 \mathrm{P}-7.5 \mathrm{~K}$ fertilizer at an annual rate of $380 \mathrm{lb} /$ acre nitrogen, $62 \mathrm{lb} /$ acre phosphorous, and $355 \mathrm{lb} /$ acre of potassium. Many of the growers also applied compost and four to six minor element sprays.

Weed Management-Weed control treatments consisted of four applications per year of glyphosate (Roundup PowerMax®; Monsanto, St. Louis, MO) applied at a rate of $11 \mathrm{lb} /$ acre per year, within rows, and four applications of pre-emergent oxadiazon (Ronstar ${ }^{\circledR}$ G; Bayers Environmental Science, Research Triangular Park, NC) applied to the containers at a rate of $8 \mathrm{lb} /$ acre per year. Rows were also mowed four to six times per year at a total cost of $\$ 120 /$ acre.

Pest Management-Pesticide usage included four applications of the slug and snail bait, metaldehyde (Deadline ${ }^{\circledR}$ Bullets; Amvac, Los Angeles, CA), at a rate of $1.6 \mathrm{lb} /$ acre per year, and one application of malathion (Malathion 5 EC; Arysta LifeScience North America, Cary, NC) at a rate of $1 \mathrm{lb} /$ acre per year. Several of the growers also used fungicide, as fungus diseases appear to be on the increase. The average cost of the treatment was included in the analysis.

Irrigation-Although pitaya is a member of the cactus family, it has a fairly high water requirement. So most pitaya growers install sprinkler irrigation systems. The cost of installing the irrigation system, including main pipes, fittings and fixtures, pumps, and digging the well, was estimated at $\$ 12,650$. Recurrent irrigation costs, which include the costs of pumping water and labor for maintenance, were estimated at $\$ 50 /$ acre per year.

Wage Rates-Based on the survey, the wage rate was assumed to be $\$ 15 / \mathrm{h}$ for skilled workers and $\$ 1 \mathrm{l} / \mathrm{h}$ for field workers. These rates included fringe benefits such as Worker's Compensation, Social Security, Medicare, and health insurance. Piece-rate wage rates were used for harvesting.

Harvesting and Marketing CostsThe cost for harvesting and transporting pitaya fruit was assumed to be $\$ 0.05 / \mathrm{lb}$.

The financial analysis was based on a discounted cash flow layout, with annual time steps and a maximum evaluation period of 20 years. The cash flow analysis was built around the following three areas: investment inputs, variable (recurrent) inputs, and returns and residual values. The model used well-known key output variables (KOVs) such as net present value (NPV), internal rate of return (IRR), benefit cost ratio (BCR), and breakeven year (Barry et al., 2000). The discount rate applied was $5 \%$ and reflected the minimum acceptable return on an investment of this nature, given that in 2010 the average yield on the 20-year U.S. Treasury Note, which is regarded as a safe investment, was about $4.3 \%$.

In addition to developing the deterministic budget, we also used the stochastic budgeting technique to determine the enterprise's likelihood 
of commercial viability over the assumed time period. As pointed out by Lien (2003), the traditional (deterministic) approach to budgeting, based on fixed-point estimates of production and prices to predict point estimates of financial results, seldom holds in reality. While sensitivity analysis is a common response to this problem, it too is limited in that the analysis does not give any indication of the likelihood of a particular result being achieved and invariably involves considering changes in only one or a couple of variables at a time. A better approach is to use stochastic budgeting, which accounts for some of the main uncertainties in the evaluation and provides indications of the distribution of the outcomes.

The stochastic budget used follows the approach outlined by Richardson (2006) and involves the following steps. First, probability distributions were assigned to the variables affected by the risk factors outlined before. Second, the stochastic values sampled from the probability distributions were used in the accounting equations to calculate production, receipts, and the KOVs. Third, the completed stochastic budget was simulated 500 times using the random values for the risky variables. The results of the 500 samples provided the information to estimate the empirical probability distribution for the unobserved KOVs. This information can be further analyzed using a cumulative distribution function (CDF) of the KOVs, such as NPV and IRR, which shows the probability of these variables being less than a given value. The probability distribution of the CDFs for NPV and IRR generated by the stochastic model provides a great deal more information about the economic viability of the proposed business than does the deterministic analysis. Thus, for any chosen value of NPV or IRR, the respective CDFs would indicate the probability of being below that value. The model was programmed in Excel (Microsoft, Redmond, WA) and simulated using the Excel Add-In, Simulation \& Econometrics to Analyze Risk@ (Simetar, College Station, TX)

As pointed out by Hardaker et al. (2004), the variables chosen to be stochastic should be those that are likely to have the biggest impact on the level of risk associated with a certain outcome. Accordingly, the stochastic variables chosen in this model were yield and price. In view of the fact that historical data were not available to empirically determine the distribution functions for either of these variables, it was necessary to assume such distributions. Accordingly, the uniform distribution and the GRKS distributions were chosen to model the yield and price variables, respectively. Among other things, these distributions were chosen, given the limited amount of information needed to generate the random variable. The uniform distribution is one for which the probability of occurrence is the same for all possible outcomes. The population of a continuous uniform distribution is defined by a minimum and a maximum value. The GRKS distribution is a twopiece normal distribution with $50 \%$ of the weight below the middle value and $2 \%$ less than the minimum, and $50 \%$ above the middle value and $2 \%$ above the maximum. The population can therefore be defined given the minimum, middle, and maximum values. The distribution is used in place of a triangular distribution when one knows only minimum information about the random variable (Richardson, 2006).

For the yield variable, given that the fruit of the pitaya can be harvested beginning in year 2 of cultivation, with production stabilizing by year 4 , and based on discussions with growers and extension specialists, it was decided to model per area yield (lb/ acre) as follows: $\mathrm{U}_{2}(10,000,15,000)$, $\mathrm{U}_{3}(15,000,20,000)$, and $\mathrm{U}_{4+}(20,000$, $22,500)$, where $U_{i}(a, b)$ represents the uniform distribution in year $i$ and $a$ and $b$ represent the minimum and maximum values (lb/acre), respectively. Hence, in year 2 , it is assumed that yield will vary from a minimum of $10,000 \mathrm{lb} /$ acre to a maximum of $15,000 \mathrm{lb} /$ acre. Moreover, it was further assumed that the pack-out rates (the percentage of crop harvested that is marketable) would vary as follows: year $2(75 \%)$, year $3(80 \%)$, years 4-9 (90\%), and years 10 onward (95\%). Achieving a $100 \%$ pack-out rate is difficult.

The price variable was assumed to follow a GRKS distribution. On the basis of information received from the local packinghouses that purchased the majority of the crop and taking into consideration the likely impact that increased imports could have on the prices, the minimum, mid$\mathrm{dle}$, and maximum prices of $\$ 0.50 / \mathrm{lb}$, $\$ 0.85 / \mathrm{lb}$, and $\$ 2 / \mathrm{lb}$, respectively, were used to generate the price variable. The stochastic yield multiplied by the packout rate times the price equals the stochastic gross receipts.

The costs of all recurrent inputs, with the exception of labor, were assumed to increase by $1 \%$ per year. Many of the growers indicated that the cost of labor was increasing at a faster pace compared with the cost of other inputs. Among other things, this was due to the increase in the minimum wage and to policies to crack down on undocumented workers. As such, the cost of labor was allowed to grow at an average annual rate of $2 \%$ over the period. It was also assumed that the five acres of land could be purchased for $\$ 200,000$. The residual value of the land was kept at $\$ 200,000$ and the residual value of irrigation system was estimated at $\$ 2650$ or $20 \%$ of the initial value. The annual net cash flow was calculated as the stochastic gross receipts plus residuals less the total cost (investment plus recurrent costs).

To compare the stochastic results with the deterministic results, the average values for the period 2009-2010 were computed based on the information obtained from growers and packinghouses. The average price was $\$ 1.25 / \mathrm{lb}$ and average marketable yields by year were $9375 \mathrm{lb} /$ acre (year 2), $14,875 \mathrm{lb} /$ acre (year 3), 18,450 $\mathrm{lb} /$ acre (years 4-9), and 19,475 lb/ acre (years 10 onward). All other variables remained the same.

\section{Results and discussion}

The results of the deterministic financial analysis (Table 1 ) indicate that the operation was financially feasible (profitable) on the basis of the assumptions and using the average price and yields. Table 1 shows an NPV of $\$ 505,255$, indicating that the discounted benefits (present value of the returns) over the 20 -year period far exceeded the discounted costs (present value of the costs) over the same period. The IRR was calculated at $16.2 \%$, implying a profitable return on investment. Among financial experts, the rule of thumb is that a return of more than $15 \%$ to investment can be considered as quite favorable. The 
Table 1. A comparison of profitability indicators associated with establishing and operating a 5 -acre $(2.0$ ha) pitaya orchard in southern Florida using deterministic and stochastic budget models.

\begin{tabular}{|c|c|c|}
\hline \multirow[b]{2}{*}{$\underline{\text { Item }}^{\mathrm{z}}$} & \multicolumn{2}{|c|}{$\operatorname{Model}^{\mathrm{x}}$} \\
\hline & Deterministic & Stochastic \\
\hline \multicolumn{3}{|l|}{ Main assumptions: } \\
\hline Enterprise scale (acres) & 5 & 5 \\
\hline Initial investment $(\$)$ & 393,744 & 393,685 \\
\hline Average recurrent input costs ( $\$ /$ acre $)$ & 7,896 & 9,094 \\
\hline Average (expected) price $(\$ / \mathrm{lb})$ & 1.25 & 1.00 \\
\hline \multicolumn{3}{|l|}{ Average (expected) marketable yield in (lb/acre) } \\
\hline Year 2 & 9,375 & 9,375 \\
\hline Year 3 & 14,875 & 14,875 \\
\hline Years 4-9 & 18,450 & 18,225 \\
\hline Years 10-20 & 19,475 & 19,238 \\
\hline \multicolumn{3}{|l|}{ Cash flow analysis: } \\
\hline Net present value (NPV) at 5\% (\$) & 505,255 & 246,227 \\
\hline Internal rate of return (IRR) (\%) & 16.2 & 10.8 \\
\hline Benefit cost ratio (BCR) at $5 \%$ & 1.93 & 1.54 \\
\hline \multicolumn{3}{|l|}{ Sensitivity (scenario) analysis: } \\
\hline \multicolumn{3}{|l|}{ NPV } \\
\hline at $3 \%$ & 707,871 & 391,804 \\
\hline at $7 \%$ & 353,319 & 138,542 \\
\hline \multicolumn{3}{|l|}{ IRR if } \\
\hline Yield or prices decreased by $10 \%(\%)$ & 13.6 & - \\
\hline Investment expenditure increased by $10 \%(\%)$ & 14.7 & 9.7 \\
\hline Inputs increased by $10 \%(\%)$ & 15.2 & 9.8 \\
\hline \multicolumn{3}{|l|}{ Threshold analysis: } \\
\hline \multicolumn{3}{|l|}{ Operation become unprofitable if: } \\
\hline Yield or prices decreased by (\%) & 39.1 & - \\
\hline Investment expenditure increased by (\%) & 136.8 & 66.7 \\
\hline Inputs increased by $(\%)$ & 106.5 & 52.0 \\
\hline \multicolumn{3}{|l|}{ Breakeven analysis: } \\
\hline Average payback period (years) & 9 & 12 \\
\hline \multicolumn{3}{|c|}{$\begin{array}{l}{ }^{2} \text { Enterprise scale, size of the pitaya orchard; initial investment, amount of money required to start a business or farm } \\
\text { operation, which includes the costs of land and capital equipment; expected value, the long-run average or the } \\
\text { weighted average of all possible values a random variable can take; NPV, a measure used to determine if a business } \\
\text { that results in a stream of benefits and costs in the future is worth undertaking, if positive the investment should be } \\
\text { made otherwise it should not; IRR, a measure of the rate of return used to evaluate the desirability of investing in } \\
\text { a business, the higher the value the more likely the business will be profitable; BCR, a measure used to compare the } \\
\text { value of benefits to the costs, a ratio greater than l is desirable; payback period, a measure use to indicate the length } \\
\text { of time required for the accumulated receipts to cover completely the initial investment, a shorter period is } \\
\text { preferred to a longer period. } \\
{ }^{y} 1 \text { acre }=0.4047 \mathrm{ha}, \$ 1 / \mathrm{acre}=\$ 2.471 \mathrm{l} / \mathrm{ha}, \$ 1 / \mathrm{lb}=\$ 2.2046 / \mathrm{kg}, 1 \mathrm{lb} / \mathrm{acre}=1.1209 \mathrm{~kg} \cdot \mathrm{ha}^{-1} \text {. } \\
{ }^{\mathrm{x} D e t e r m i n i s t i c, ~ m o d e l ~ i n ~ w h i c h ~ a l l ~ v a r i a b l e ~ a r e ~ f i x e d ~ o r ~ k n o w n ~ w i t h ~ c e r t a i n t y, ~ f o r ~ e x a m p l e ~ t h e ~ p r i c e ~ i s ~ k n o w n ~ w i t h ~} \\
\text { certainty; stochastic, model in which some of the variables are random, that is, they are determined by chance and } \\
\text { hence are not fixed or predictable. }\end{array}$} \\
\hline
\end{tabular}

benefit-cost ratio was calculated at 1.93 , implying that for each dollar invested, the operator would earn almost twice that amount. The breakeven analysis indicates that it would take 9 years on average for the accumulated revenues to equal the accumulated cost (i.e., for the accumulated net cash flow to equal zero). In other words, it would require 9 years for the investor to recoup all of his/her investment. obtained in the case of changes in investment expenditures and seasonal inputs, although the impact on the IRR was of lesser magnitude. For instance, a $10 \%$ increase in either variable would cause the IRR to decline from $16.2 \%$ to $14.7 \%$ and $15.2 \%$, respectively.

A threshold analysis, or stress test, was also conducted to determine the extent of changes in any of the variables (yield, prices, investment expenditures, or seasonal inputs) that would be necessary to make the NPV equal to zero. As alluded to earlier, in light of the inherent risks involved in agriculture, an NPV of zero at a given interest rate implies that the operation is not profitable given that similar returns could be obtained elsewhere from a less risky alternative. The results of the analysis as shown in Table 1 indicate that yield or prices would have to decline by $39.1 \%$, whereas investment expenditure or seasonal inputs would have to increase by $136.8 \%$ or $106.5 \%$, respectively.

Table 1 , in addition to showing the results of the deterministic model, also shows the results for the stochastic values based on the expected (average) values for the stochastic variables, whereas Fig. I shows the results of the CDF of the stochastic NPV and the cut-off point for the NPV obtained from the deterministic model (indicated in the chart by the vertical line). Compared with the deterministic NPV value of $\$ 505,255$, the stochastic average NPV was $\$ 246,227$, with a standard deviation of $\$ 93,438$ and a coefficient of variation $(\mathrm{CV})$ of $37.9 \%$. The minimum and maximum NPVs were $-\$ 19,032$ and $\$ 541,286$, respectively (Table 2 ). In general, the stochastic budget supports the deterministic budget, namely that the investment is economically viable, but it provides additional information on the distributions of the net returns. For instance, it shows that the NPV from the deterministic model is to the extreme right of the distribution (Fig. 1). It also indicates that even though highly unlikely, there is a small chance (probability of less than 1\%) that the investment could be unprofitable over the period. This is reflected by the small portion of the CDF that lies to the left (negative NPV) of the $\mathrm{y}$-axis.

A similar analysis was performed for the IRR (Fig. 2). The data used 


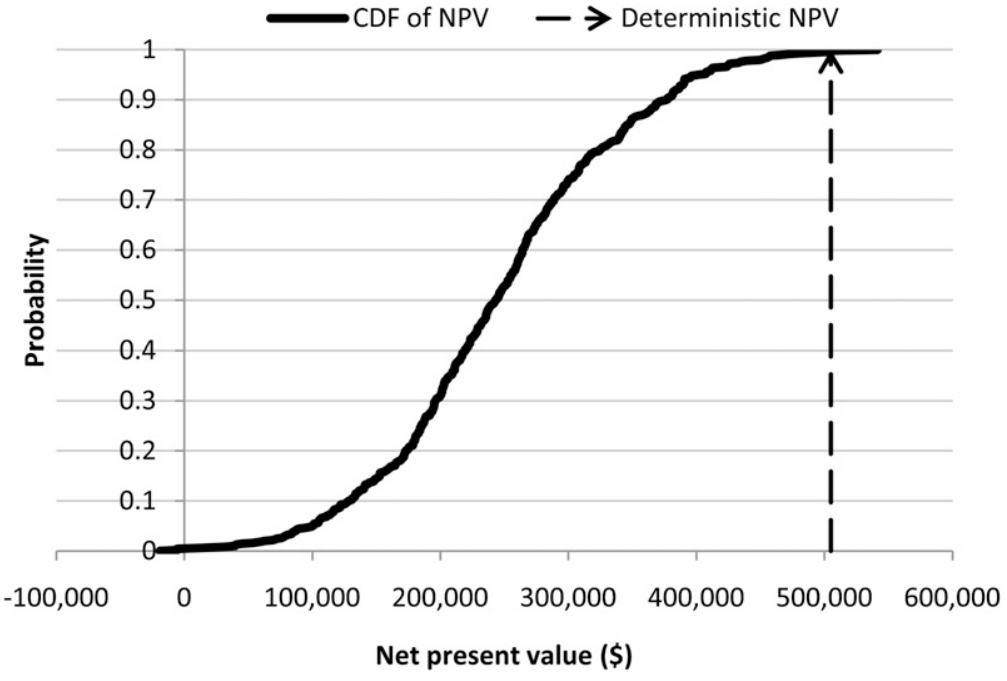

Fig. 1. The cumulative distribution function (CDF) of net present value (NPV) of a 5 -acre $(2.0 \mathrm{ha}$ ) pitaya orchard, showing the likelihood (probability) that the NPV will be less than any chosen value. CDF of NPV indicates that the probability of the NPV will be less than a given value. By choosing a value on the $\mathrm{x}$-axis and making a vertical line to the CDF and then a horizontal line to the $y$-axis, the probability that the NPV will be less than the starting value is given on the $y$-axis. For example, by choosing the value of $\$ 505,255$, which was obtained from the deterministic model (shown by the broken line in the figure), the CDF indicates that the probability of obtaining a value less than this is $0.99(99 \%)$. The probability that the NPV would be less than $\$ 300,000$ is about $0.31(31 \%)$. The probability of the NPV falling between two values can be found by subtracting the probabilities of each. Thus the probability of the NPV being less than $\$ 505,255$ but more than or equal to $\$ 300,000$ is $0.68(0.99-0.31)$ or $68 \%$. The probability that the NPV would be less than zero (which would imply that the operation is not profitable) is less than 0.01 (1\%). Deterministic NPV indicates the NPV that could be expected based on the assumptions of the deterministic model.

Table 2. A comparison of the mean, SD, CV, minimum and maximum values obtained for the net present value (NPV), and internal rate of return (IRR) using deterministic and stochastic budgeting models to assess profitability of a 5-acre (2.0 ha) pitaya orchard in southern Florida.

\begin{tabular}{lcccc}
\hline & \multicolumn{4}{c}{ Model $^{\mathrm{y}}$} \\
\cline { 2 - 5 } Item $^{\mathbf{z}}$ & Stoch_npv & Deter_npv & Stoch_irr & Deter_irr \\
\hline Mean & $\$ 246,227$ & $\$ 505,255$ & $10.9 \%$ & $16.2 \%$ \\
SD & $\$ 93,438$ & - & $2.3 \%$ & - \\
CV & $37.9 \%$ & - & $20.7 \%$ & - \\
Min & $-\$ 19,032$ & $\$ 505,255$ & $4.5 \%$ & $16.2 \%$ \\
Max & $\$ 541,286$ & $\$ 505,255$ & $17.5 \%$ & $16.2 \%$ \\
\hline
\end{tabular}

${ }^{2}$ Min, minimum value; Max, maximum value.

'Stoch_npv, summary statistics for the net present value results from the stochastic model; Deter_npv, summary statistics for the net present value results from the deterministic model; Stoch_irr, summary statistics for the internal rate of return results from the stochastic model; Deter_irr, summary statistics for the internal rate of return results from the deterministic model.

in Fig. 2 indicate that the stochastic average IRR was $10.9 \%$ and the deterministic IRR was $16.2 \%$, both representing a decent return on investment. As discussed earlier, the stochastic budget provides additional information and shows that the standard deviation was $2.3 \%$, with a CV of $20.7 \%$. The minimum IRR was $4.5 \%$, slightly less than our target rate of $5 \%$ and the maximum was $17.5 \%$ (Table 2 ). fruit" because of its high levels of antioxidants and nutrients, such as lycopene, and its versatility, and so it is becoming increasingly popular with health-conscious consumers and highend restaurant chefs.

The purpose of this study was to assess the financial feasibility of operating a 5-acre pitaya orchard in southern Florida and to assess the risks of doing so given recent developments that are likely to add to production and marketing risks. Deterministic and stochastic budgeting techniques were used to determine the enterprise's likelihood of commercial viability over the assumed time period of 20 years. The latter (stochastic budgeting) was done by conducting a simulation risk analysis using stochastic price and yield variables with all other variables kept the same as in the deterministic model. Prices were assumed to follow a GRKS distribution and yields were modeled as a uniform distribution.

Results of both the deterministic and simulation risk analyses suggested that operating a pitaya orchard would likely be profitable over the planning horizon. Although both approaches were in agreement, the simulation risk analysis allowed for a more realistic portrayal of the operation by allowing prices and yields to vary over the period. It also provided the decision maker with additional insights to the likely outcome (probabilities) for KOVs, such as NPV and IRR. Thus, in relation to the NPV, the simulation risk analysis revealed a stochastic average NPV of \$246,227 compared to a deterministic average NPV of $\$ 505,255$. It further revealed that, even though very unlikely, there was a small probability (less than 1\%) that the operation could be unprofitable. Likewise, there is a small probability (less than 1\%) that the NPV could exceed the deterministic value. The fact that the cumulative distribution was skewed mainly to the right further implies an increased likelihood that the operation would be profitable. Similar results were obtained with regard to the IRR, with the average returns for the stochastic and deterministic models being $10.9 \%$ and $16.2 \%$, respectively.

Despite the favorable outcome of the analysis, southern Florida growers are advised to proceed with caution as the market for the crop 


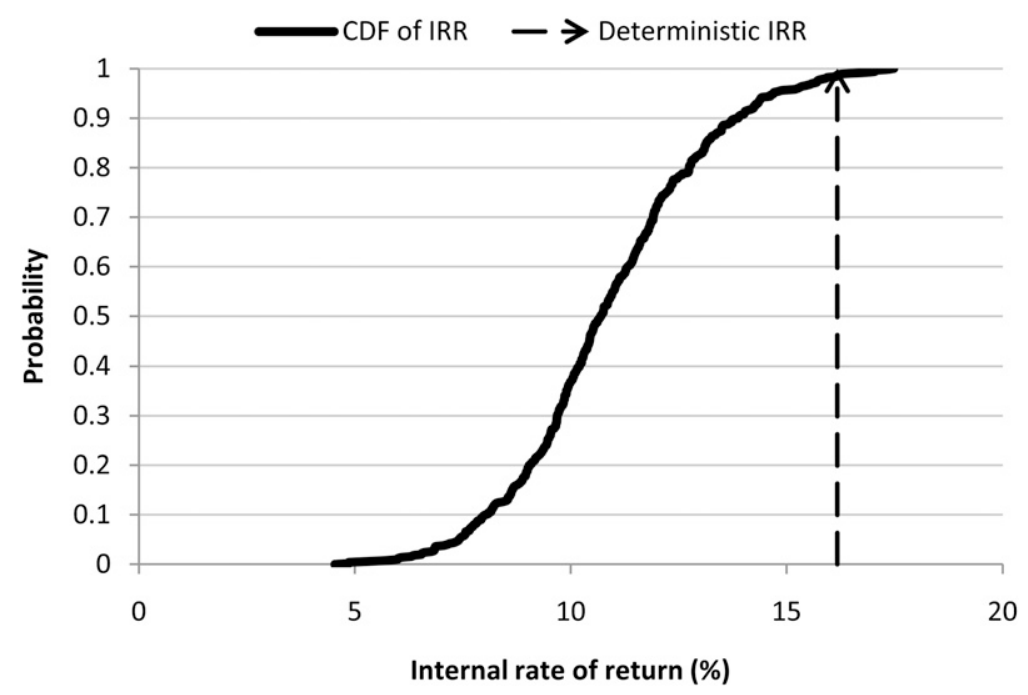

Fig. 2. The cumulative distribution function (CDF) of internal rate of return (IRR) from an investment in a 5 -acre $(2.0 \mathrm{ha})$ pitaya orchard, showing the likelihood (probability) that the rate of return will be less than any chosen value. CDF of IRR indicates the probability the IRR will be less than a given value. The CDF indicates that the likelihood of obtaining a rate of return that is less than the $16.2 \%$ (indicated by the broken line in the figure) suggested by the deterministic model is $0.98(98 \%)$. In other words, there is only a small probability (less than $2 \%$ ) of obtaining such a high rate of return. Deterministic IRR indicates the rate of return that could be expected based on the assumptions of the deterministic model.

could easily be oversupplied by domestic and foreign competitors. Though there are opportunities for streamlining and improving the production process for pitaya using advanced technologies (e.g., flowering could be induced with artificial lights), a careful analysis of costs vs. returns would need to be conducted to determine if the increase in production efficiency would justify the additional costs.

\section{Literature cited}

Barry, P., P. Ellinger, J. Hopkin, and C. Baker. 2000. Financial management in agriculture, 6th ed. Interstate, Danville, IL.
Crane, J.H. and C.F. Balerdi. 2005. The Pitaya (Hylocereus undatus and other spp.) in Florida. Trop. Res. Educ. Ctr., Univ. of Florida, Homestead, 18 Nov. 2011. <http://miami-dade.ifas.ufl.edu/ pdfs/tropical_fruit/THE $\% 20$ PITAYA $\% 20$ in $\% 20$ Florida.pdf $>$.

Evans, E.A. 2006. Value Added Agriculture: Is it Right for Me? Univ. of Florida, Dept. Food Resource Econ. FE638, 10 Sept. 2010. <http://edis.ifas.ufl.edu/ FE638>

Evans, E.A., J. Huntley, J. Crane, and A.F. Wysocki. 2010. 2010 Cost Estimates of Establishing and Producing Pitaya (dragon fruit) in South Florida. Univ. of Florida, Dept. Food Resource Econ. FE888, 17 Dec. 2010. <http://edis.ifas.ufl. edu/FE888>.
Gunasena, H.P.M., D.K.N.G. Pushpakumara, and M. Kariyawasam. 2006. Dragon fruitHylocereus undatus (Haw.) Britton and Rose: Field manual for extension workers. Sri Lanka Council Agr. Policy, Wijerama Mawatha, Colombo, Sri Lanka.

Hardaker, J.B., R.B.M. Huirne, J.R. Anderson, and G. Lien. 2004. Coping with risk in agriculture. 2nd ed. $C A B$ International, Wallingford, UK.

Lien, G. 2003. Assisting whole-farm decision-making through stochastic budgeting. Agr. Syst. 76:399-413.

Lobo, R. and G. Bender. 2008. Pitahay Field Test Yields Preliminary Results. Small Farm News 2:10, 9 Sept. 2010. <http://sfp.ucdavis.edu/pubs/sfnews / 200802 news.pdf $>$.

Mizrahi, Y., A. Nerd, and P.S. Nobel. 1997. Cacti as crops. Hort. Rev. 18:321346.

Palmateer, A. and R.C. Ploetz. 2006. Anthracnose of pitahaya: A new disease on a new crop in south Florida. Proc. Florida State. Hort. Soc. 119:50-51.

Richardson, J.W. 2006. Simulation for applied risk management. Dept. Agr. Econ., Agr. Food Policy Ctr., Texas A\&M Univ., College Station.

Steele, D. and J.H. Crane. 2006. The state of the Florida tropical fruit industry and the challenges growers face. Proc. Florida State. Hort. Soc. 119:7-8.

U.S. Department of Agriculture. 2008. Questions and Answers: Importing Vietnamese Dragon Fruit to the United States. Animal Plant Health Inspection Serv. Plant Protection and Quarantine Factsheet. 1 Sept. 2010. <http://www. aphis.usda.gov/publications/plant_ health/content/printable_version/faq_ dragonfruit_08.pdfs. 